\title{
Employment Effects of Service Offshoring: Evidence from Matched Firms
}

\author{
Rosario Crinò \\ Institut d'Anàlisi Econòmica, CSIC
}

December, 2009

\begin{abstract}
This paper studies the effects of service offshoring on the level and skill composition of domestic employment, using a rich data set of Italian firms and propensity score matching techniques. The results show that service offshoring has no effect on the level of employment but changes its composition in favor of high skilled workers.
\end{abstract}

JEL codes: F1.

Keywords: Service Offshoring; Employment; Skills; Propensity Score Matching; Sensitivity Analysis.

*Mailing Address: Institut d'Anàlisi Econòmica CSIC, Campus UAB, 08193 Bellaterra, Barcelona, Spain. E-mail: rosario.crino@iae.csic.es. Phone: +34 935806612 . Fax: +34 935801452. 


\section{Introduction}

The rapid improvements in information and communication technologies occurred over the last decade have reduced the cost of trading services across national borders and have allowed firms located in developed countries to transfer abroad an increasing number of service activities (service offshoring). The potential consequences of this new phenomenon for the level and skill composition of domestic employment have been extensively debated in the media (see Mankiw and Swagel, 2006, for a summary) and have become the object of a rapidly growing number of empirical studies (see Crinò, 2009a, for a review). So far, the literature suggests that service offshoring has small effects on the level of domestic employment (see, e.g., Amiti and Wei, 2005; and Liu and Trefler, 2008) but changes its composition in favor of high skilled workers (see, e.g., Geishecker and Görg, 2008; and Crinò, 2009b). Such effects reflect the fact that the developed countries offshore low skill-intensive services and specialize in more complex tasks, so that low skilled jobs are replaced by high skilled jobs with little change in total employment.

Three important limitations imposed by data constraints, however, have plagued most of the empirical research so far. In particular, the existing studies were generally forced to: (1) limit the analysis to aggregate industries (Görg and Hanley, 2005, being a relevant exception); (2) use offshoring proxies estimated under restrictive assumptions; and (3) employ empirical models based on strong functional-form restrictions. This paper aims to overcome these limitations and to provide new empirical evidence on the employment effects of service offshoring. To this purpose, it takes advantage of a large and rich data set of Italian firms including information on service offshoring and uses Propensity Score Matching (PSM) techniques, which require no functional-form assumptions.

In implementing PSM, the paper explicitly deals with the possibility that service offshoring (the treatment) and level and skill composition of employment (the outcomes) be jointly influenced not only by 'observable', but also by 'unobservable' characteristics. To the best of our knowledge, this is one of the few studies accounting for unobservable factors when using PSM to investigate the employment effects of international-trade-related phenomena. 
A notable exception is the work by Becker and Muendler (2008) on the effects of foreign employment expansions by German multinational firms.

The results confirm that service offshoring has no effect on total employment but changes its composition in favor of high skilled workers. Because they are based on service offshoring information at the firm-level and on a different and more general approach, these findings strengthen and generalize the main conclusions of previous research.

\section{Data}

The data come from the $9^{\text {th }}$ 'Indagine sulle Imprese Manifatturiere', the most recent wave of a large survey of Italian firms administered every three years by the commercial bank UnicreditCapitalia. The survey collects information on internationalization activities, investment, R\&D and characteristics of the workforce. The $9^{\text {th }}$ wave was carried out in 2003 . Some of the questions were only asked for that year, whereas others were asked either for all the years since 2001 or cumulatively for the period 2001-2003. Balance sheet data available continuously since 2001 complement the survey questions. The original sample consists of 4,111 firms and is stratified by size class, geographic area and industry to be representative of the enterprises with more than 10 employees. After dropping firms with missing values for the variables of interest, the final estimation sample includes 3,079 firms.

Unlike the previous waves, the $9^{\text {th }}$ contains questions on service offshoring; they refer to the activities carried out in 2003. ${ }^{1}$ In particular, firms are asked whether they purchased services from abroad (Amiti and Wei, 2005) in that year, and the types of services they imported. Two treatment indicators are constructed from these questions: the variable $S O S$ taking a value of 1 if the firm offshored any types of services, and the variable $S O S_{B U S}$ taking a value of 1 only if the firm offshored business services. ${ }^{2}$ Treated firms are 516 in the first case and 287 in the second; control (non-offshoring) firms are always 2,563. The outcome variables are the (log) number of employees and the share of workers with a college degree at the end of

\footnotetext{
${ }^{1}$ The previous waves, instead, included questions on production offshoring, whose employment effects are studied by Antonietti and Antonioli (2007).

${ }^{2}$ The difference between $S O S$ and $S O S_{B U S}$ is represented by firms offshoring transportation services only.
} 
2003.

Panel a) of Table 1 reports descriptive statistics on the outcomes by offshoring status. The offshoring firms have both higher employment and a more skilled workforce compared with the non-offshoring firms. As shown in panel b), however, the offshoring firms do not constitute a random sample because, before treatment, they differed from the non-offshoring firms along many observable characteristics. Because the latter may have jointly influenced the subsequent offshoring decision and the outcomes of these firms, any causal inference based on the simple comparison of the outcomes by offshoring status is invalid. PSM eliminates this bias by comparing offshoring and non-offshoring firms that are equivalent in terms of pretreatment observable characteristics. The next section presents PSM and sketches the main idea beyond a sensitivity analysis for the cases in which unobservable characteristics, too, influence service offshoring and the outcomes.

\section{Empirical Strategy}

Let $i=1, \ldots, N\left(\equiv N_{T}+N_{C}\right)$ index firms, where $N_{T}$ and $N_{C}$ are the numbers of treated and control units, respectively. Also, let $T_{i}=\{0,1\}$ indicate the treatment status of each firm. (In this paper, $T_{i}=1$ if the $i$-th firm offshores services and $T_{i}=0$ otherwise.) Finally, define with $Y_{1, i}$ and $Y_{0, i}$ the potential outcomes of firm $i$ with and without treatment, respectively. The Average Treatment effect on Treated firms $(A T T)$ is:

$$
A T T \equiv E\left(Y_{1, i}-Y_{0, i} \mid T_{i}=1\right)=E\left(Y_{1, i} \mid T_{i}=1\right)-E\left(Y_{0, i} \mid T_{i}=1\right)
$$

While $E\left(Y_{1, i} \mid T_{i}=1\right)$ is observed, $E\left(Y_{0, i} \mid T_{i}=1\right)$ is not, because the same firm cannot be in both treatment statuses at the same time. However, $E\left(Y_{0, i} \mid T_{i}=1\right)$ can be estimated from the outcomes of control firms under the following identifying assumptions:

1. Conditional Independence Assumption (CIA): $Y_{0, i} \perp T_{i} \mid X_{i}$;

2. Common Support Assumption: $\operatorname{Pr}\left(T_{i}=1 \mid X_{i}\right)<1$. 
CIA states that, conditional on the vector of covariates $X_{i}$, the potential outcomes in the absence of treatment are independent of treatment status, as if treatment were randomized: conditioning on $X_{i}$, therefore, accounts for all of the factors affecting treatment and outcomes at the same time. The missing information $E\left(Y_{0, i} \mid T_{i}=1\right)$ can then be imputed by matching each treated firm to the control firms with the same values of $X_{i}$ and using the outcomes of the matched firms as estimates. The Common Support Assumption ensures that there exist both treated and control firms with the same $X_{i}$.

Following Rosenbaum and Rubin (1983), in this paper firms are matched not on $X_{i}$ directly, but on the propensity score, $p\left(X_{i}\right)$. This is defined as the probability of receiving treatment given $X_{i}$, i.e. $p\left(X_{i}\right) \equiv \operatorname{Pr}\left(T_{i}=1 \mid X_{i}\right)$, and is estimated by logit. Single nearest-neighbor matching with replacement is then used to pair each treated firm to the control firm with the closest value of the estimated propensity score. The ATT is computed as the average difference between the outcomes of the matched pairs of firms:

$$
A T T=\frac{1}{N_{T}} \sum_{k=1}^{N_{T}}\left(Y_{k}-\frac{1}{N_{C m(k)}} \sum_{j=1}^{N_{C m(k)}} Y_{j(k)}\right)
$$

where $N_{C m(k)}$ is the number of control firms $(j)$ matched to the $k$-th treated firm. ${ }^{3}$

If treatment and outcomes are also influenced by unobservable characteristics, then CIA fails and the ATT's are biased. The size of the bias depends on the strength of the correlation between the unobservable factors, on the one hand, and treatment and outcomes, on the other. The main idea beyond a sensitivity analysis is to study whether the baseline results obtained under CIA would substantially change, or even overturn, if this assumption were violated. Ichino et al. (2008) assume that CIA is violated by an unobserved variable ('confounder'), and propose to simulate it in the data and use it together with $X_{i}$ to re-estimate $p\left(X_{i}\right)$ and to compute a new $A T T$. Comparing the $A T T$ 's estimated with and without the confounder yields an indication of how the results would change if CIA were violated. The confounder can be simulated to match the distribution of different relevant variables, thereby allowing

\footnotetext{
${ }^{3} N_{C m(k)}=1$, unless there is more than one control firm with the same value of the estimated propensity score.
} 
one to assess the implications of different sources of violation.

In sum, PSM will compare the level and skill composition of employment in the offshoring firms with those in a subsample of non-offshoring firms as similar as possible in terms of observable characteristics. The outcomes of the matched firms will be used to estimate those of the offshoring firms in the unobservable counterfactual scenario in which they have not engaged in service offshoring. This approach relies on the assumption that firms' selection into offshoring is entirely determined by observable characteristics (CIA): in this case, conditioning on the observed covariates makes service offshoring resemble a randomized treatment. CIA fails, however, if unobservable factors such as a favorable productivity shock in 2003 simultaneously lead firms to engage in service offshoring and to change level and skill composition of their workforce. The sensitivity analysis will verify that such unobservable confounders are not strong enough to explain the entire difference in outcomes between the matched groups of firms.

\section{Results}

The matching is implemented for four specifications of the propensity score, each estimated for both treatment indicators. The first specification only conditions on the 'structural variables' listed in panel b1) of Table 1, the second adds the 'training, investment and technology variables' in panel b2), the third further adds the 'internationalization variables' in panel b3), and the fourth also controls for lagged import penetration (the ratio of imports over apparent consumption in 2002) at the level of 2-digit NACE industries; all the covariates enter linearly in all the specifications. The common support restriction is implemented by deleting the offshoring firms whose propensity score is higher than the maximum or lower than the minimum propensity score of the matched non-offshoring firms. ${ }^{4}$

Covariate balancing tests reported in the web appendix ${ }^{5}$ show that the matching is effective in removing differences in observable characteristics between offshoring and non-offshoring

\footnotetext{
${ }^{4}$ Estimation and testing are performed in Stata 10, using the psmatch2 and pscore routines developed by Leuven and Sianesi (2003).

${ }^{5}$ Available at http://crino.iae-csic.org.
} 
firms. In particular, the median absolute bias is reduced by $72-91 \%$ depending on the treatment and specification of the propensity score. The Pseudo- $R^{2}$ after matching is always close to zero, correctly suggesting that the covariates have no explanatory power for predicting service offshoring in the matched samples. Also, the number of offshoring firms outside the common support is fairly small, ranging from 1 to 11.

Table 2 reports the estimated ATT's with analytical standard errors. For comparison, it also reports OLS estimates from regressions of the outcomes on a constant and the treatments. Panel a) refers to total employment. Note that, although OLS confirm that the offshoring firms have higher employment, all the $A T T$ 's are small and statistically insignificant. Hence, service offshoring has no causal effect on the level of domestic employment: the unconditional difference between the two groups of firms vanishes out once observed covariates are controlled for.

Service offshoring does play an important role, instead, in changing the composition of employment in favor of high skilled workers. The ATT's reported in panel b), in fact, are all positive and very precisely estimated, and their point estimates suggest that the effects of service offshoring are economically large. For instance, the results for the fourth specification of the propensity score show that overall service offshoring $(S O S)$ raises the share of college graduates by 1.8 percentage points, i.e. by three-fourths of the unconditional difference between offshoring and non-offshoring firms detected by OLS.

Sensitivity checks reported in the web appendix show that these results are robust to: (1) the use of alternative matching estimators (i.e., single nearest-neighbor without replacement in both ascending and descending order, multiple nearest-neighbor with 10 matches, radius with 1\% caliper, epanechnikov kernel with 0.06 bandwidth); (2) the use of trimming (1\% caliper) as an alternative procedure to impose the common support restriction; (3) the inclusion of controls for lagged outcomes (i.e., log employment and shares of white-collar and R\&D workers in 2002) in the specification of the propensity score.

Table 3 investigates to what extent the results depend on unobservable characteristics correlated with service offshoring and the outcomes. To this purpose, the ATT's are re- 
estimated using simulated confounders with the same empirical distribution as the firm-level covariates reported in Table 1. To save space, only the results for the fourth (and richest) specification of the propensity score are reported. ${ }^{6}$ Starting from total employment in panel a), note that the $A T T$ 's are all small and statistically insignificant. This is not surprising, indeed, given that the baseline ATT's were already imprecisely estimated. Turning to the share of college graduates in panel b), note that the ATT's are all positive and precisely estimated, although their values are systematically lower than in Table 2. This suggests that unobservable characteristics bias the baseline estimates upward: for instance, a confounder behaving like labor productivity would account for 0.7 percentage points (i.e., 0.18 - 0.11) of the baseline $A T T$ of $S O S$. Importantly, however, none of the confounders are strong enough to overturn the main results: indeed, the strongest unobservable factor simulated in Table 3 would still leave SOS explain more than one-third (0.9 percentage points) of the unconditional difference between offshoring and non-offshoring firms.

\section{Conclusion}

The results of this paper suggest that service offshoring may have relevant compositional effects even within individual firms, and that these effects favor high skilled workers. Hence, improved access to higher education and on-the-job training programs may represent effective measures to mitigate the adjustment costs in developed countries.

\section{Acknowledgements}

The author thanks an anonymous referee for very useful comments. Financial support from the Barcelona GSE research network and the Government of Catalunya is gratefully acknowledged.

\footnotetext{
${ }^{6}$ The sensitivity analysis is performed using the sensatt routine developed by Nannicini (2007). This routine simulates a binary confounder with the same distribution as the specified covariate. (Continuous covariates need to be discretized: this paper uses sample averages as the cut-off points.) The simulated confounder is then treated as an additional regressor in the estimation of the propensity score and in the subsequent computation of the ATT. The procedure is repeated for a large number of simulations of the confounder (500 in this paper) and the final $A T T$ is calculated as the average of the individual $A T T$ 's across all the simulations. The standard error is computed as $s e=\sqrt{s e_{W}^{2}+\left(1+\frac{1}{S}\right) s e_{B}^{2}}$, where $S$ is the number of simulations, $s e_{W}^{2}$ is the average variance of the $A T T$ across all the simulations, and $s e_{B}^{2}$ is the average deviation of the $A T T$ from its mean.
} 
The usual disclaimer applies.

\section{References}

[1] Amiti, M. and S.J. Wei, 2005, "Fear of Service Outsourcing: Is It Justified?," Economic Policy, 20(42), pp. 308-347

[2] Antonietti, R. and D. Antonioli, 2007, "Production Offshoring and the Skill Composition of Italian Manufacturing Firms: A Counterfactual Analysis," FEEM Working Paper 97.2007

[3] Becker, S.O. and M.A. Muendler, 2008, "The Effect of FDI on Job Security," The B.E. Journal of Economic Analysis $\&$ Policy, 8(1), article 8

[4] Crinò, R., 2009a, "Offshoring, Multinationals and Labour Market: A Review of the Empirical Literature," Journal of Economic Surveys, 23(2), pp. 197-249

[5] Crinò, R., 2009b, "Service Offshoring and White-Collar Employment," The Review of Economic Studies, forthcoming

[6] Geishecker, I. and H. Görg, 2008, "Service Offshoring and Wages: Evidence from Micro Data," IZA Discussion Paper 3593

[7] Görg, H. and A. Hanley, 2005, "Labour Demand Effects of International Outsourcing: Evidence from Plant-Level Data," International Review of Economics and Finance, 14(3), pp. $365-376$

[8] Ichino, A., F. Mealli and T. Nannicini, 2008, "From Temporary Help Jobs to Permanent Employment: What Can We Learn From Matching Estimators and Their Sensitivity?," Journal of Applied Econometrics, 23(3), pp. 305-327

[9] Leuven, E. and B. Sianesi, 2003, "Psmatch2: Stata Module to Perform Full Mahalanobis and Propensity Score Matching, Common Sport Graphing, and Covariate Imbalance Testing," available at http://ideas.repec.org/c/boc/bocode/s432001.html

[10] Liu, R. and D. Trefler, 2008, "Much Ado About Nothing: American Jobs and the Rise of Service Outsourcing to China and India," NBER Working Paper 14061

[11] Mankiw, G.N. and P. Swagel, 2006, "The Politics and Economics of Offshore Outsourcing," Journal of Monetary Economics, 53(5), pp. 1027-1056

[12] Nannicini, T., 2007, "A Simulation-Based Sensitivity Analysis for Matching Estimators," The Stata Journal, 7(3), pp. 334-350

[13] Rosenbaum, P.R. and B. Rubin, 1983, "Central Role of the Propensity Score in Observational Studies for Causal Effects," Biometrika, 1(70), pp. 41-55 


\begin{tabular}{|c|c|c|c|c|c|c|c|}
\hline \multirow{3}{*}{ 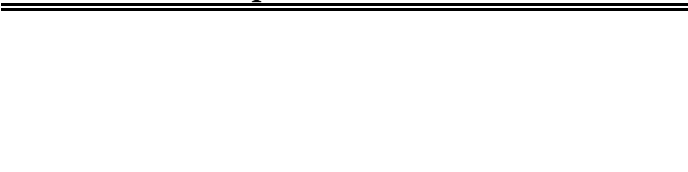 } & \multirow{3}{*}{$\begin{array}{r}\text { Firms: } \\
\text { Treatment: }\end{array}$} & \multirow{2}{*}{\multicolumn{2}{|c|}{$\begin{array}{c}\text { Control }\left(\mathrm{N}_{\mathrm{C}}=2,563\right) \\
-\end{array}$}} & \multirow{2}{*}{\multicolumn{2}{|c|}{$\begin{array}{l}\text { Treated }\left(\mathrm{N}_{\mathrm{T}}=516\right) \\
\text { SOS }\end{array}$}} & \multirow{2}{*}{\multicolumn{2}{|c|}{$\begin{array}{c}\text { Treated }\left(\mathrm{N}_{\mathrm{T}}=287\right) \\
\qquad \text { SOS }_{B U S}\end{array}$}} \\
\hline & & & & & & & \\
\hline & & Mean & Std. Dev. & Mean & Std. Dev. & Mean & Std. Dev. \\
\hline \multicolumn{8}{|l|}{ a) Outcomes } \\
\hline Log Employment, 2003 & & 3.776 & 0.911 & 4.353 & 1.063 & 4.508 & 1.125 \\
\hline Share of College Graduates, 2003 & & 0.047 & 0.069 & 0.072 & 0.084 & 0.085 & 0.098 \\
\hline \multicolumn{8}{|l|}{ b) Pre-Treatment Characteristics } \\
\hline \multicolumn{8}{|l|}{ b1) Structural Variables } \\
\hline Log Output, 2002 & & 15.907 & 1.135 & 16.661 & 1.199 & 16.819 & 1.233 \\
\hline Log Average Wage, 2002 & & 10.271 & 0.492 & 10.347 & 0.594 & 10.396 & 0.543 \\
\hline Log Value Added per Worker, 2002 & & 11.404 & 0.655 & 11.534 & 0.714 & 11.546 & 0.677 \\
\hline Log Inputs per Worker, 2002 & & 11.299 & 1.071 & 11.584 & 1.001 & 11.581 & 0.952 \\
\hline Log Capital per Worker, 2002 & & 10.201 & 1.188 & 10.397 & 1.238 & 10.346 & 1.304 \\
\hline Share of Workers with Fixed-Term Contracts, 2002 & & 0.037 & 0.119 & 0.040 & 0.106 & 0.035 & 0.085 \\
\hline Indicator: Quoted on the Stock Market & & 0.008 & 0.088 & 0.016 & 0.124 & 0.017 & 0.131 \\
\hline Indicator: Belongs to a Group & & 0.243 & 0.429 & 0.440 & 0.497 & 0.467 & 0.500 \\
\hline Indicator: Credit Constrained & & 0.139 & 0.346 & 0.136 & 0.343 & 0.111 & 0.315 \\
\hline \multicolumn{8}{|l|}{ b2) Training, Investment and Technology Variables } \\
\hline Share of Workers in Professional Training Courses, 2002 & & 0.045 & 0.120 & 0.082 & 0.171 & 0.088 & 0.185 \\
\hline R\&D / Sales, 2002 & & 0.016 & 0.327 & 0.016 & 0.087 & 0.015 & 0.049 \\
\hline ICT Share of Total Investment, 2001-2003 & & 0.107 & 0.184 & 0.118 & 0.174 & 0.117 & 0.162 \\
\hline \multicolumn{8}{|l|}{ b3) Internationalization Variables } \\
\hline Indicator: Foreign Direct Investment & & 0.025 & 0.155 & 0.078 & 0.268 & 0.070 & 0.255 \\
\hline Indicator: Participated by a Foreign Firm & & 0.056 & 0.230 & 0.151 & 0.359 & 0.209 & 0.407 \\
\hline Indicator: Exporter & & 0.700 & 0.459 & 0.926 & 0.261 & 0.937 & 0.243 \\
\hline Indicator: Offshored Intermediate Inputs & & 0.164 & 0.371 & 0.252 & 0.435 & 0.293 & 0.456 \\
\hline
\end{tabular}

Source: Unicredit-Capitalia. The treatment indicator SOS takes a value of 1 if the firm offshored any types of services in 2003 . SOS BUS takes a value of 1 only if the firm offshored business services. Control firms are those with no service offshoring. 
Table 2 - Baseline Results

\begin{tabular}{|c|c|c|c|c|c|c|c|c|c|c|}
\hline & \multicolumn{5}{|c|}{ a) Outcome: Log Employment } & \multicolumn{5}{|c|}{ b) Outcome: Share of College Graduates } \\
\hline & \multirow[t]{2}{*}{ OLS } & \multicolumn{4}{|c|}{ ATT } & \multirow[t]{2}{*}{ OLS } & \multicolumn{4}{|c|}{ ATT } \\
\hline & & Spec. 1 & Spec. 2 & Spec. 3 & Spec. 4 & & Spec. 1 & Spec. 2 & Spec. 3 & Spec. 4 \\
\hline \multirow[t]{2}{*}{ Treatment: SOS } & $0.577 * * *$ & 0.025 & 0.028 & 0.021 & -0.026 & $0.024 * * *$ & $0.018^{* * *}$ & $0.018^{* * *}$ & $0.015^{* * *}$ & $0.018^{* * *}$ \\
\hline & {$[0.050]$} & {$[0.069]$} & {$[0.070]$} & {$[0.072]$} & {$[0.070]$} & {$[0.004]$} & {$[0.005]$} & {$[0.005]$} & {$[0.005]$} & {$[0.005]$} \\
\hline \multirow[t]{2}{*}{ Treatment: $S O S_{B U S}$} & $0.732 * * *$ & -0.023 & 0.002 & 0.004 & -0.070 & $0.038^{* * *}$ & $0.024^{* * *}$ & $0.020 * *$ & $0.023^{* * *}$ & $0.028^{* * *}$ \\
\hline & {$[0.069]$} & {$[0.093]$} & {$[0.096]$} & {$[0.092]$} & {$[0.093]$} & {$[0.006]$} & {$[0.008]$} & {$[0.008]$} & {$[0.008]$} & {$[0.007]$} \\
\hline
\end{tabular}


Table 3 - Sensitivity Analysis

\begin{tabular}{|c|c|c|c|c|}
\hline Outcome: & \multicolumn{2}{|c|}{ a) Log Employment } & \multicolumn{2}{|c|}{ b) Share of College Graduates } \\
\hline Treatment: & SOS & $\operatorname{SOS}_{B U S}$ & sos & $S_{O S} S_{B U S}$ \\
\hline
\end{tabular}

Confounder behaving like:

Log Output, 2002

Log Average Wage, 2002

\begin{tabular}{|c|c|c|c|}
\hline 0.019 & 0.049 & $0.010^{* *} *$ & $0.021 * * *$ \\
\hline$[0.041]$ & [0.049] & {$[0.004]$} & {$[0.005]$} \\
\hline 0.017 & 0.029 & $0.010^{* * *}$ & $0.020 * * *$ \\
\hline$[0.041]$ & {$[0.051]$} & [0.003] & {$[0.005]$} \\
\hline 0.018 & 0.021 & $0.011^{* * *}$ & $0.021 * * *$ \\
\hline$[0.038]$ & {$[0.052]$} & {$[0.003]$} & {$[0.005]$} \\
\hline 0.021 & 0.026 & $0.011^{* * *}$ & $0.021^{* * *}$ \\
\hline$[0.042]$ & {$[0.052]$} & {$[0.003]$} & {$[0.005]$} \\
\hline 0.008 & 0.007 & $0.012^{* * *}$ & $0.023^{* * *}$ \\
\hline$[0.038]$ & {$[0.047]$} & {$[0.003]$} & {$[0.005]$} \\
\hline 0.013 & 0.006 & $0.012^{* * *}$ & $0.023^{* * *}$ \\
\hline$[0.038]$ & {$[0.050]$} & [0.003] & [0.004] \\
\hline-0.006 & -0.007 & $0.013^{* * *}$ & $0.025^{* * *}$ \\
\hline$[0.034]$ & [0.041] & [0.003] & [0.004] \\
\hline 0.016 & 0.033 & $0.009 * *$ & $0.020^{* * *}$ \\
\hline [0.039] & {$[0.054]$} & [0.004] & {$[0.005]$} \\
\hline-0.003 & -0.002 & $0.013^{* * *}$ & $0.025^{* * *}$ \\
\hline$[0.034]$ & [0.041] & [0.003] & [0.004] \\
\hline 0.016 & 0.021 & $0.011^{* * *}$ & $0.022^{* * *}$ \\
\hline [0.039] & {$[0.053]$} & [0.004] & {$[0.005]$} \\
\hline 0.009 & 0.021 & $0.011^{* * *}$ & $0.021^{* * *}$ \\
\hline [0.039] & {$[0.055]$} & [0.004] & {$[0.005]$} \\
\hline 0.010 & 0.008 & $0.012^{* * *}$ & $0.022 * * *$ \\
\hline$[0.038]$ & [0.049] & {$[0.003]$} & {$[0.004]$} \\
\hline 0.002 & 0.002 & $0.012^{* * *}$ & $0.023^{* * *}$ \\
\hline$[0.040]$ & {$[0.050]$} & [0.004] & {$[0.005]$} \\
\hline 0.008 & 0.026 & $0.011^{* * *}$ & $0.021 * * *$ \\
\hline$[0.041]$ & [0.059] & [0.004] & {$[0.006]$} \\
\hline 0.014 & 0.021 & $0.010^{* *}$ & $0.022^{* * *}$ \\
\hline$[0.042]$ & {$[0.051]$} & {$[0.004]$} & {$[0.005]$} \\
\hline 0.013 & 0.018 & $0.012^{* * *}$ & $0.023^{* * *}$ \\
\hline [0.039] & {$[0.053]$} & {$[0.003]$} & {$[0.005]$} \\
\hline
\end{tabular}

Log Value Added per Worker, 2002

Log Inputs per Worker, 2002

Log Capital per Worker, 2002

Share of Workers with Fixed-Term Contracts, 2002

Indicator: Quoted on the Stock Market

Indicator: Belongs to a Group

Indicator: Credit Constrained

Share of Workers in Professional Training Courses, 2002

R\&D / Sales, 2002

ICT Share of Total Investment, 2001-2003

Indicator: Foreign Direct Investment

Indicator: Participated by a Foreign Firm

Indicator: Exporter

Indicator: Offshored Intermediate Inputs

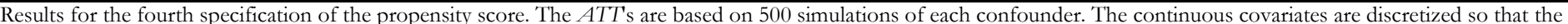

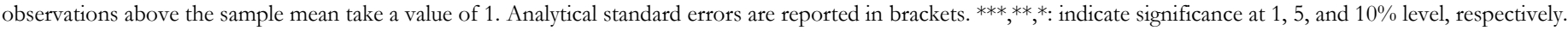

